childhood absence seizures and Landau-Kleffner syndrome but not with other epilepsy syndromes. EEGs were improved in $28 \%$ of patients with idiopathic epilepsy compared to $18 \%$ with symptomatic epilepsy. (Akman CI, Holmes GL. The effect of lamotrigine on the EEGs of children and adolescents with epilepsy. Epilepsy \& Behavior August 2003;4:420423). (Respond: Cigdem I Akman MD, Columbia University College of Physicians and Surgeons, Division of Pediatric Neurology, 180 Fort Washington Ave, New York, NY 10032).

COMMENT. LTG add-on therapy improves EEG background activity in addition to decreasing the frequency of interictal and ictal epileptiform discharges. Interictal EEG abnormalities are reduced especially in patients with complex partial seizures, absence, and idiopathic epilepsies. Improvements in the EEG may be expected even in children with severe intractable epilepsy.

Adjunctive LTG therapy in 54 patients, 12 years of age or older, with refractory epilepsy and mental retardation showed decreased seizure frequency and improved behavior in an open-label multicenter study, while the dosage of concomitant antiepileptic drugs was reduced. (McKee JR, Sunder TR, FineSmith R et al. Epilepsy \& Behavior Aug 2003;4:386-394).(Respond: JR McKee PhD, Pharmacy Department, Western Carolina Center, 300 Enola Rd, Morgantown, NC 28655).

Reversible neurotoxicity (confusion and disorientation) occurred in 3 adult patients with absence status epilepticus following administration of an IV bolus and oral doses of valproic acid. LTG levels were elevated (18-22 $\mathrm{mcg} / \mathrm{mL})$ compared to baseline (2.9-7.7 $\mathrm{mcg} / \mathrm{mL}$ ), whereas serum VPA and ammonia levels were in the normal range. Improvement correlated with discontinuing or reducing the dosage of LTG. (Burneo JG, Limdi N, Kuzniecky RI et al. Neurology June (2 of 2) 2003;60:1991-1992).

\title{
REVERSIBLE ALTERED CONSCIOUSNESS AND BRAIN ATROPHY INDUCED BY VALPROIC ACID
}

A 5-year-old female child with valproic acid (VPA)-related alteration of consciousness and brain atrophy that progressed over a 3 day period and resolved within 12 hours of discontinuing VPA is reported from Dokkyo University School of Medicine and Shimotsuga General Hospital, Tochigi, Japan. Seizures began at 2 years of age, EEG showed bilateral temporai and central focal spikes, and treatment with VPA ( $15 \mathrm{mg} / \mathrm{kg} / \mathrm{d})$ was effective until a generalized clonic seizure occurred at 5 years. CT was normal, VPA serum level was $25.7 \mathrm{mcg} / \mathrm{mL}$, and the dose was increased to $20 \mathrm{mg} / \mathrm{kg} / \mathrm{d}$, resulting in a serum level of $76.4 \mathrm{mcg} / \mathrm{mL}$. After 3 months on this dose and over a period of 3 days, she developed an alteration of consciousness. She had difficulty stating her name and had little interest in her surroundings. Neurologic examination, liver function tests and serum ammonia were normal. VPA level was $107 \mathrm{mcg} / \mathrm{mL}$, the CT showed enlargement of cerebral sulci and evidence of brain atrophy, and the EEG awake revealed diffuse background slowing. VPA was discontinued, and consciousness level returned to normal within 12 hours. After 1 week, a repeat EEG was normal, and serial CT showed improvement within 1 month and normal appearance in 2 months. Phenobarbital was substituted, and at 5 month follow-up, her behavior and mental function were normal. (Yamanouchi H, Ota T, Imataka G et al. Reversible altered consciousness with brain 
atrophy caused by valproic acid. Pediatr Neurol May 2003;28:382-384). (Respond: Dr Yamanouchi, Department of Pediatrics, Dokkyo University School of Medicine, 880 Kitakobayashi, Mibu, Shimotsuga, Tochigi 321-0293, Japan).

COMMENT. Reversible dementia and pseudoatrophy of the brain associated with valproate treatment have been reported previously (McLachlan RS (1987), Papazian O et al (1995), and Guerrini R et al (1998) - authors' citations). The differential diagnosis includes VPA-related encephalopathy with hyperammonemia, mitochondrial disorders, cytochrome c deficiency, carnitine deficiency with hepatic failure, and paradoxical VPAinduced status absence. Changes in consciousness during treatment with VPA should suggest possible drug toxicity and reversible cerebral atrophy.

The safety and efficacy of IV valproate in pediatric status epilepticus is reported in 18 patients from Harbor-UCLA Medical Center, Torrance, CA (Yu K-T et al. Epilepsia May 2003;44:724-726). All 18 patients regained baseline mental status within 1 hour of seizure cessation. Post-infusion plasma VPA levels ranged from 51 to $138 \mathrm{mcg} / \mathrm{ml}$.

\section{NEUROMUSCULAR DISORDERS}

\section{MYOPATHIC MITOCHONDRIAL DNA DEPLETION SYNDROME}

Three siblings with the myopathic form of mitochondrial DNA depletion syndrome and a homozygous mutation in the TK2 gene are reported from Columbia University College of Physicians and Surgeons, New York, NY. They developed normally until 12 to 16 months of age, when walking was delayed, limb muscles became progressively weak and hypotonic, and death from respiratory failure occurred at ages 23 to 40 months. Muscle biopsy showed $40 \%$ to $60 \%$ ragged-red cytochrome c oxidase negative fibers. All affected siblings had decreased activity of respiratory chain complexes. Southern blot analysis showed reduction of mitochondrial DNA-nuclear DNA ratio in muscle, indicating severe mitochondrial DNA depletion. Sequencing of the TK2 gene showed a homozygous mutation in exon 5. (Mancuso M, Filosto M, Bonilla E et al. Mitochondrial myopathy of childhood associated with mitochondrial DNA depletion and a homozygous mutation (T77M) in the TK2 gene. Arch Neurol July 2003;60:1007-1009). (Reprints: Salvatore DiMauro MD, Department of Neurology, 4-420 Columbia University College of Physicians and Surgeons, $630 \mathrm{~W} 168^{\text {th }}$ St, New York, NY 10032).

COMMENT. Patients with the myopathic form of mitochondrial depletion syndrome (MDS) present with progressive weakness, hypotonia, and areflexia at or shortly after birth. Death from respiratory failure occurs before 1 year of age in the congenital form and before 10 years in the juvenile form. Primary mitochondrial DNA depletion is inherited as an autosomal recessive trait. In patients with predominant muscle involvement and mtDNA depletion, the TK2 gene should be screened for mutations, making prenatal diagnosis possible.

The minimum birth prevalence for mitochondrial respiratory chain disorders presenting by 16 years of age is estimated at 6.2/100,000 in an Australian study at Royal Children's Hospital, Melbourne (Skladal D, Halliday J, Thorburn DR. Brain August 2003;126:1905-1912). Pathogenic mtDNA mutations were identified in $12 \%$ of diagnosed cases and pathogenic nuclear gene mutations in a further $12 \%$. 